\title{
Quad-band FSS for Electromagnetic Shielding
}

\author{
Alka Singh ${ }^{2,}$, Chitra Singh ". \\ "Centre for Advanced Studies, Dr. A.P.J. Abdul Kalam Technical University, New Campus, Lucknow, \\ Uttar Pradesh-226031 \\ * Corresponding Author: alka87025@gmail.com, chitrasingh.rpl@gmail.com
}

Received: 11-03-2021, Revised: 01-05-2021, Accepted: 03-05-2021, Published: 30-05-2021

\begin{abstract}
In this paper, a novel method to design Quad-band stop frequency selective surface (FSS) is proposed to shield medical/non-medical devices from electromagnetic radiation of wifi/Bluetooth, GPS, 1G, 2G, 3G, 4G and 5G frequencies. The proposed device can also be used in security and surveillance devices to protect them from electromagnetic attack. The FSS unit cell consists of convoluted structures on FR4 substrate. The study was performed by designing individual frequency selective surfaces for $1 \mathrm{G}, 2 \mathrm{G}, \mathrm{Wi}-\mathrm{Fi} / \mathrm{Bluetooth}, \mathrm{GPS}, 4 \mathrm{G}$ and $5 \mathrm{G}$, then combining it to form a single Quad-band FSS unit.
\end{abstract}

Keywords: FSS, Quadband FSS, Ultra-Wideband FSS Electromagnetic Shielding

\section{Introduction}

Frequency Selective Surfaces (FSS) are the periodic structures or 3-D/2-D arrays of elements, that are used to attenuate, transmit or reflect, the electromagnetic frequencies. The periodic structure that repeats itself is called unit cell, these unit cells are fabricated in a dielectric substrate, and this together forms a frequency selective surface. The problem of electromagnetic interference (EMI) is prominent in medical equipment's (ECG machine, Pulse Oximeter, Ventilators etc.), devices like Pace maker, insulin pumps, cochlear implants, in telecommunication, and in communication between home automation devices. The potential sources of EMI are Mobile devices, Microwave Ovens, Bluetooth devices, Wi-fi, electromagnetic pest control devices etc.

As world is moving towards $5 \mathrm{G}$ and home automation, in near future the problem of electromagnetic interference and health problems related to electromagnetic radiation will need more attention. The designed FSS can shield a device from a wide range of frequencies, providing attenuation. 
The current paper focuses on providing with an effective, low cost, Quad bandFSS design, with high attenuation against electromagnetic interference, and effective shielding from electromagnetic waves.

\section{Design Methodology}

The FSS Unit cells are designed using CST Software. Table 1

Table 1. Target frequencies for various FSS Structures

\begin{tabular}{|c|c|c|c|c|}
\hline S.No. & Generation & & Frequency Range & References \\
\hline 1. & $1 \mathrm{G}$ & 0.80 & $-0.900 \mathrm{GHz}, 0.82 \mathrm{GHz}-0.89 \mathrm{GHz}$ & [1] [2] \\
\hline 2. & $2 \mathrm{G}$ & $0.850-$ & TDMA 824- 894 MHz & {$[1][3],[4]$} \\
\hline & & $\begin{array}{l}1.900 \\
\mathrm{GHz}\end{array}$ & CDMA $1850-1990 \mathrm{MHz}$ & \\
\hline 3. & $3 \mathrm{G}$ & $1.6-2.5$ & $\mathrm{xHz}, \mathrm{UMTS} 2.1 \mathrm{GHz}, 1.8-2.5 \mathrm{GHz})$ & {$[1][4][5][6]$} \\
\hline 4. & $4 \mathrm{G}$ & $2-8 \mathrm{G}$ & $\begin{array}{l}\mathrm{z}, 0.8,0.9,1.8,2.1,2.6 \mathrm{GHz} \text { (IMT } \\
\text { dvanced), } 750 \mathrm{MHz}-2.6 \mathrm{GHz}\end{array}$ & {$[1][7][4]$} \\
\hline 5. & $5 \mathrm{G}$ & $3-300$ & $\begin{array}{c}\text { Lower Frequencies 3.4-5GHz Mid } \\
\text { Freq }\end{array}$ & [1] [8] \\
\hline & & & $\begin{array}{c}\text { Higher Frequencies 27GHz, } 37 \\
\text { GHz, } 39 \mathrm{GHz}\end{array}$ & \\
\hline 6. & Wi-Fi & $2.412-2$ & $83 \mathrm{GHz}, 2.4 \mathrm{GHz}, 5.15-5.725 \mathrm{GHz}$ & {$[9][10],[11] .[4]$} \\
\hline 7. & Bluetooth & & $2.407-2.480 \mathrm{GHz}, 2.4$ & {$[9],[4]$} \\
\hline 8. & WiMAX & & $5.8 \mathrm{GHz}$ & [10] \\
\hline 9. & GPS & 1.57 & $-1.5764 \mathrm{GHz}, 1.23 \mathrm{GHz}, 1.57 \mathrm{GHz}$ & {$[9],[4]$} \\
\hline 10. & X Band & & 8-12 GHz, 8.2-12.4GHz & {$[12],[13]$} \\
\hline 11. & $\mathrm{Ku}$ Band & & 12-18 GHz,12.4-18GHz & {$[14,15,16]$} \\
\hline 12. & $\begin{array}{c}\text { Airborne US245 } \\
\text { Radar }\end{array}$ & & $3.500-3.600 \mathrm{MHz}$ & [7] \\
\hline
\end{tabular}

shows the list of communication bands that are targeted to be stopped by FSS, in this work. The final design is a convoluted structure, with design on both sides of the substrate. The 
convoluted structures are a group of complex geometries, consists of conducting grids, arrays and slotted structures, that are interweaved, turned and folded, to form a unit cell of FSS.

These designs offer greater advantage of stopping multiple range of frequencies, reduced cell size, ease of fabrication, stability with various incident angles and polarizations, and also helps in effectively isolating devices from interfering electromagnetic signals.

The basic principle of working of FSS is the geometry of structure and periodicity of unit cell in FSS results in resonance, this frequency is called resonant frequency (fr). For a good FSS design the distance between substrate and patch is kept at least $0.5 \mathrm{~mm}$.

For an FSS structure to show stable resonance with different incident angles, interelemental spacing must be smaller than $0.4 \lambda$. In a convoluted FSS structure, if the unit cell dimensions remain as small as $4.48 \%$ of free space wavelength at resonant frequency, the structure shows stability with incident angles and polarization variations.

\section{A. Design Simulated for various frequencies}

The table 2 shows the periodicity of the simulated structure, with different frequencies, the dielectric material (substrate) used is FR4 (Lossy, $\varepsilon_{\mathrm{r}}=4.3$ ), with thickness $1.6 \mathrm{~mm}$. The copper (annealed) material is used as a patch material with uniform thickness of $0.035 \mathrm{~mm}$.

The value of element size is calculated by finding $\lambda$ e, which is given by

$\lambda=\frac{\lambda_{c}}{\sqrt{\sqrt{\epsilon}_{e}}}$ where, $\lambda_{c}=\frac{c}{f_{c}}$

$\mathrm{fc}_{\mathrm{c}}$ is the mid frequency of the frequency band to be stopped and $\mathrm{c}$ is the speed of light.

When $\left(\frac{W}{H}<1\right)$ the value of $\epsilon_{e}$ is given by:

$\epsilon_{e}=\frac{\epsilon_{r}+1}{2}+\frac{\epsilon_{r}-1}{2}\left(1+12\left(\frac{H^{-\frac{1}{2}}}{W}\right)\right)+0.04\left(1-\left(\frac{W^{2}}{H}\right)\right)$.

When $\left(\frac{W}{H} \geq 1\right)$ the value of $\epsilon_{e}$ is given by:

$\epsilon_{e}=\frac{\epsilon_{r}+1}{2}+\frac{\epsilon_{r}-1}{2}\left(1+12\left(\frac{H^{-\frac{1}{2}}}{W}\right)\right)$.

Where, $\epsilon_{r}$ is relative dielectric constant of substrate, $\mathrm{W}$ is the width of element and $\mathrm{H}$ is the height of substrate (dielectric height). The width of element is dependent upon periodicity of unit cell [5]. 
Using the above parameters, for a frequency $(f)$, the dimensions of patch can be estimated. Table 2 shows the target bandwidth, estimated frequency, periodicity and other properties of simulated design using equation 1 (i.e., $\left(\frac{W}{H}<1\right)$ ).

Table 2. Simulated Designs, Target Bandwidth and Simulated Frequency

\begin{tabular}{|c|c|c|c|c|c|}
\hline $\begin{array}{c}\text { Wireless } \\
\text { Technology/ } \\
\text { frequencies } \\
\text { Stopped }\end{array}$ & Range fH-fL & fC & $\begin{array}{c}\text { FBW= } \\
\text { fH-fL/fC } \\
* 100\end{array}$ & (dB) RL at fp & $\begin{array}{c}\text { Periodicity (in } \\
\text { terms } \boldsymbol{\lambda o} \text { ) }\end{array}$ \\
\hline $1.8 \mathrm{GHz}(2 \mathrm{G}, 4 \mathrm{G})$ & $2.00-1.61$ & 0.3 & 200 & 33.73 & $0.64^{*} 0.64$ \\
\hline $0.8 \mathrm{GHz}(4 \mathrm{G}, 1 \mathrm{G})$ & $0.93-0.77$ & 0.16 & 188.42 & 34.02 & $30.0^{*} 30.0$ \\
\hline $2.3 \mathrm{GHz}(3 \mathrm{G})$ & $2.57-2.06$ & 0.25 & 200.03 & 33.34 & $0.28^{*} 0.28$ \\
\hline $3.5 \mathrm{GHz}(5 \mathrm{G})$ & $3.99-3.00$ & 0.50 & 200 & 34.08 & $0.30^{*} 0.30$ \\
\hline $1.5 \mathrm{GHz}(\mathrm{GPS})$ & $2.013-1.17$ & 0.42 & 200.71 & 38.01 & $0.133^{*} 0.133$ \\
\hline $4.39 \mathrm{GHz}(5 \mathrm{G})$ & $5.18-3.44$ & 0.87 & 200 & 37.01 & $0.32^{*} 0.32$ \\
\hline 2.4GHz (wi-fi) & $2.80-1.89$ & 0.46 & 200 & 35 & $0.144^{*} 0.144$ \\
\hline $5.7 \mathrm{GHz}$ (Wi-Fi, Wi- & $6.58-5.00$ & 0.79 & 200 & 34.01 & $0.14^{*} 0.14$ \\
Max) & & & & & \\
\hline
\end{tabular}

\section{FBW: FRACTIONAL BANDWIDTH}

Periodicity $(\mathrm{P})$ is given by,

$P=n X \lambda_{c}=n X \frac{c}{f_{c}}$

Where, $f_{c i s}$ given by $f_{H}+\frac{f_{L}}{2}, f_{L}$ is lower and $f_{H}$ is the higher range of frequency band to be stopped. For a successful design the value of $f_{c}$ should be closer to FSS structure's resonant frequency, $f_{r}$, therefore for further design discussions $f_{c}$ will be considered equal to $f_{r}$.

Phase range is also an important parameter to decide Fractional Bandwidth of FSS. In previous studies it is demonstrated for a square loop based system that FBW is proportional to the change in phase range $[17,18]$. In this research, a method is developed to predict FBW by tuning simulated phase range $(\phi 2)$ equal to the analytical phase range $(\phi 1)$.

The conducting lines of FSS can be considered as a series combination of a capacitor and an inductor. If the overall capacitance of FSS is higher it acts as band stop FSS, when overall 
inductance is higher the FSS acts as band pass filter. Also, this can be correlated from the fact that patch-type FSS are mostly used in Band Stop Filter, while slot-types are preferred for Band Pass Filter [19,20].

Following are the various designs simulated for various frequencies:

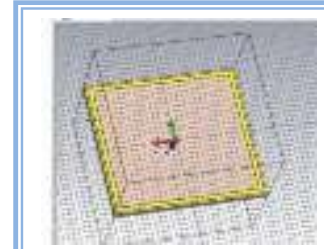

(a)

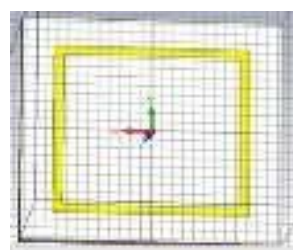

(d)

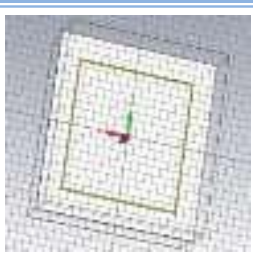

(b)

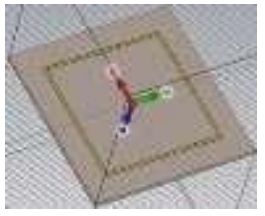

(e)

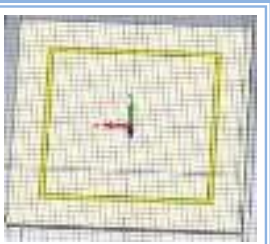

(c)

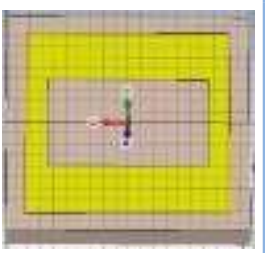

(f) $5 G$

Figure 1. List of Simulated Design Using Single Structure

\section{B. Design using Superposition of Structures}

In this method FSS are designed by superimposing various structures obtained from stop band FSS discussed in section A. Following are the designs that are simulated by superimposing various frequencies.
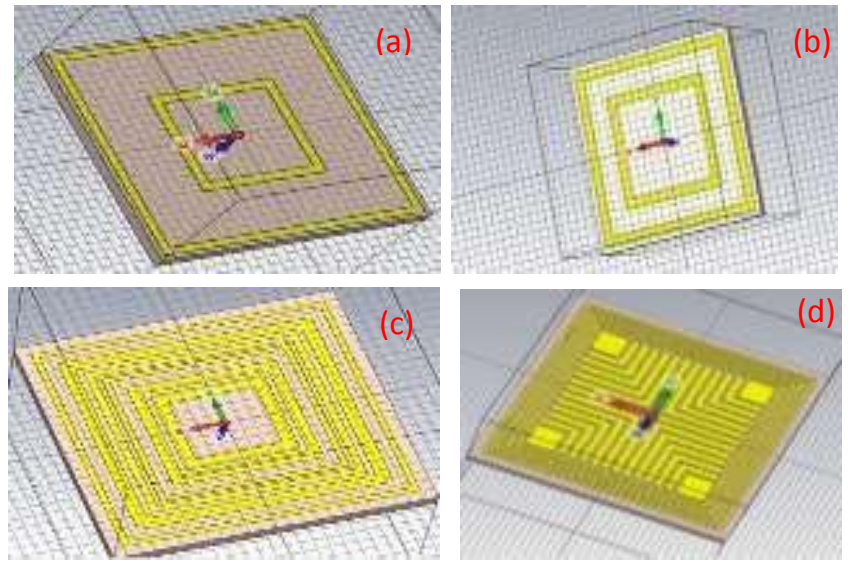

Figure 2. List of Simulated Design using Superposition of Structures

Design 2 (b) and (d) are simulated in an attempt to stop the higher and lower $\mathrm{Wi}-\mathrm{Fi}$ frequencies. 


\section{Design Using Both Sides of Substrate}

It was observed that various frequencies can be stopped using design at both sides of substrate, remarkable results are obtained for the following frequencies:

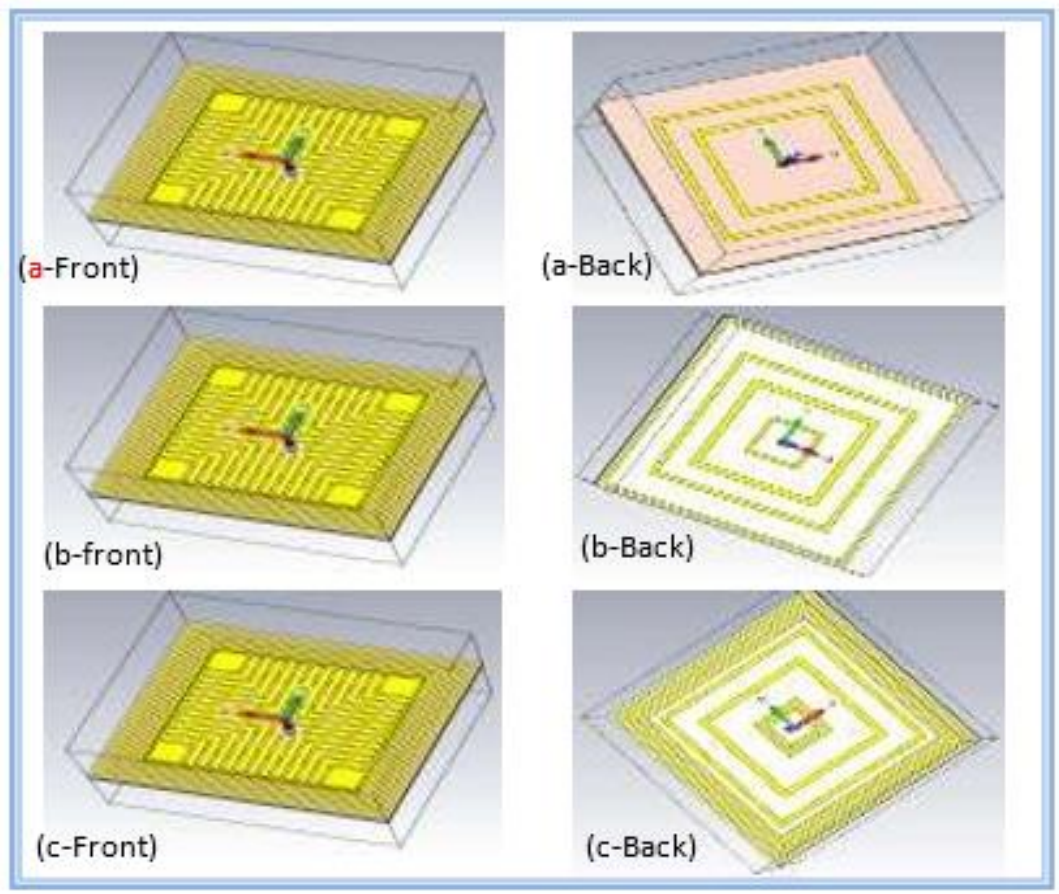

Figure 3. List of figures designed using both sides of Substrate

\section{Results and Discussion}

Scattering parameters are used to describe a relationship between input and output ports, using incident and reflected power, of a two-port system.

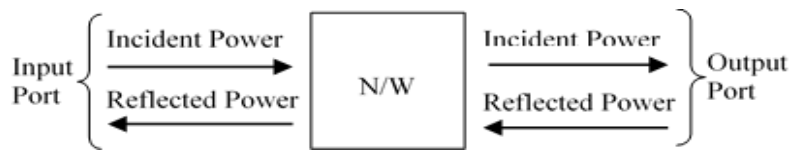

Figure 5. Illustration of Scattering Parameters

The S11 parameter can also be described as, Input Return Loss (RLin),

Where,

$$
\mathrm{RLin}=-20 \log 10|\mathrm{~S} 11|
$$

For FSS band stop device, 
- S11 should be ideally infinite, as it is the ratioof reflected power at input port to the incident power. More the reflection at the input port, lesser the power will be transmitted to the output port. For $\mathrm{S} 11=0 \mathrm{~dB}$, all the power will be transmitted to output port, due to negligible reflection. Thus more negative the value of RLin (equation 4), better is the FSS device for band stop applications.

- Similarly, S21is the power at output port to the incident power at input port. Thus, for FSS band stop device S21should be ideally $0 \mathrm{~dB}$; lesser the value of S21better is the device for FSS band stop design.

Since in CST STUDIO, the value $\mathrm{SZmax}(1), \mathrm{Zmax}(1)$ is $\mathrm{S} 11$ at TE Mode, while SZmin(1), Zmax(1) is S21 at TE Mode. Similarly, S2max (2) Zmax (2) are considered reflection parameters at TM mode.

The results indicate the stability of design in both TE and TM Mode. The S11 (Blue), S21 (Red) and reflection parameter

\section{A. Results of Designs (a) to ( $f$ )}

The figure 6 shows the S-parameter results obtained for the simulated designs (a) to (f), for phase $0^{\circ}$.

For the simulated designs (a) to (f) the range of frequencies stopped, and value of scattering parameters $(\mathrm{dB})$ is shown in table 3 .

Table 3. Details obtained from Scattering Parameter Graph

\begin{tabular}{|l|l|l|l|}
\hline \multicolumn{1}{|c|}{$\begin{array}{c}\text { Design } \\
\text { Name }\end{array}$} & $\begin{array}{c}|c| \\
\text { Range of } \\
\text { Frequencies (GHz) }\end{array}$ & \multicolumn{1}{|c|}{ Mid Frequency (GHz) } & S11 (dB) \\
\hline (a) & $0.77-0.94$ & $1.5625(\mathrm{GPS})$ & -37.55 \\
\hline (b) & $0.93-0.77$ & $\begin{array}{l}0.8536(1 \mathrm{G} .2 \mathrm{G} \text { TDMA, 4G (IMT } \\
\text { Advanced }\end{array}$ & 30.72 \\
\hline (c) & $2.055-2.567$ & $2.308(3 \mathrm{G})$ & -32.84 \\
\hline (d) & $3.00-3.99$ & $\begin{array}{l}3.504 \quad \text { (5GLower frequencies, } \\
\text { Airborne US245 Radar) }\end{array}$ & \\
\hline (e) & $1.605-1.99$ & $1.803(2 \mathrm{G} /$ IMT Advanced 4G) & -33.41 \\
\hline (f) & $3.27-5.22$ & $4.32(5 \mathrm{G})$ & -37.98 \\
\hline
\end{tabular}

Design (f) is showing a deviation from transmission parameters of TE Mode, other than that for all other design, there is a perfect overlapping between TE mode transmission 
parametersand TM mode reflection parameters, indicating good stability of designs in both TE and TM modes.

From the results above it can be shown that by tuning the geometry of a single loop (using equation 1 or 2), the individual frequencies can be stopped without affecting other frequencies.

The value of S11 obtained in the range of -30.72 to $-38.01 \mathrm{~dB}$ is showing comparatively good performance in comparison to previous reported work.

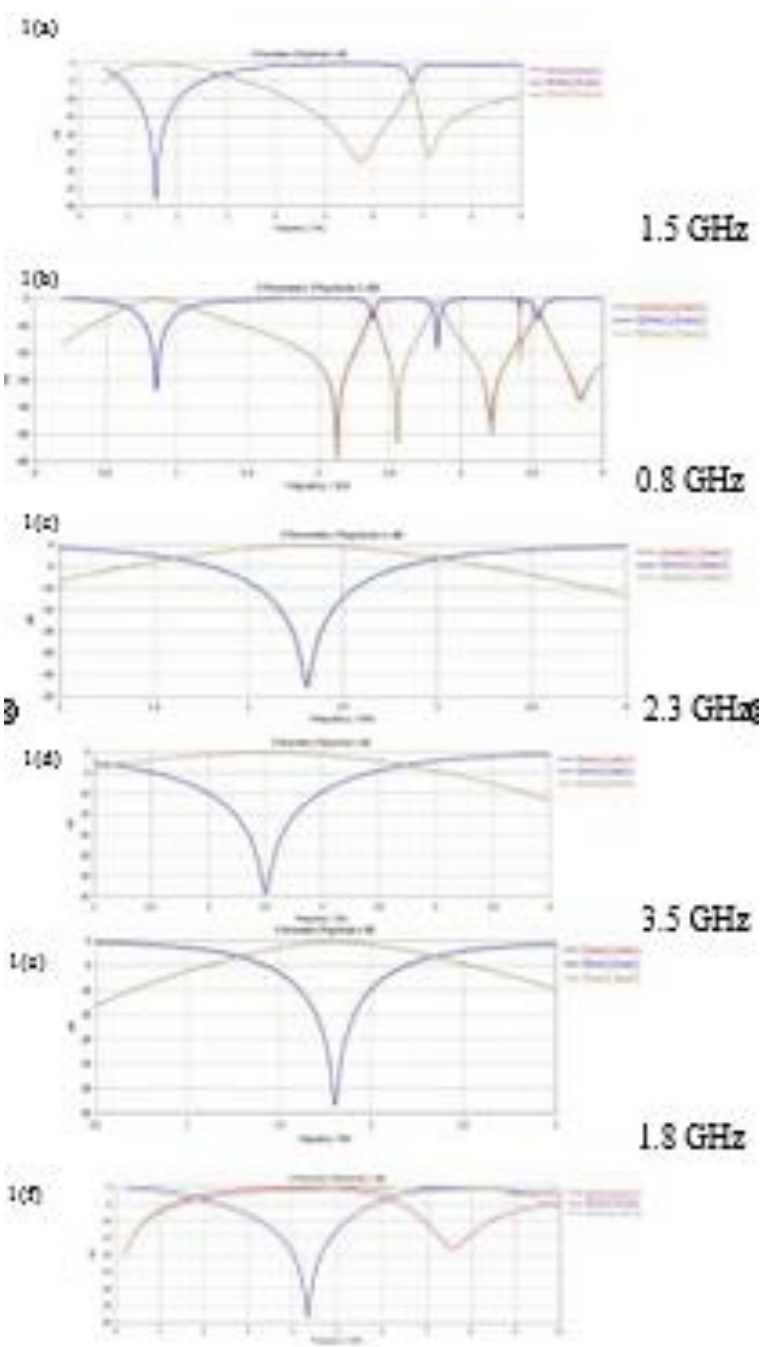

5G

Figure 6. S-Parameter of Results Obtained 


\section{B. Results of Designs 2 (a) to (d)}

For the simulated designs (g) to (j) following are the range of frequencies stopped, and value of scattering parametersin $\mathrm{dB}$.

Table 4. Details obtained from Scattering Parameter Graph and

Graphical representation of scattering parameters obtained

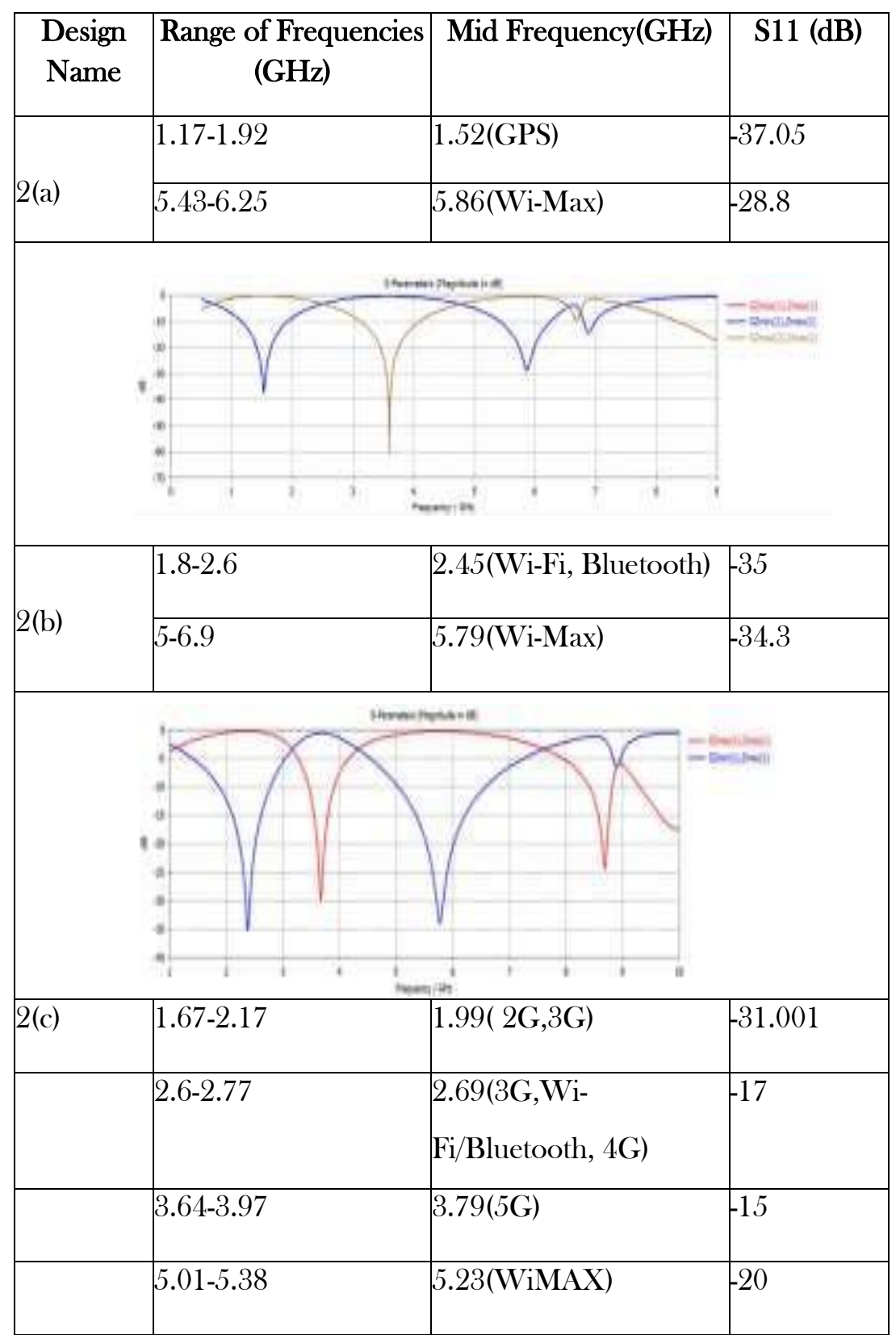




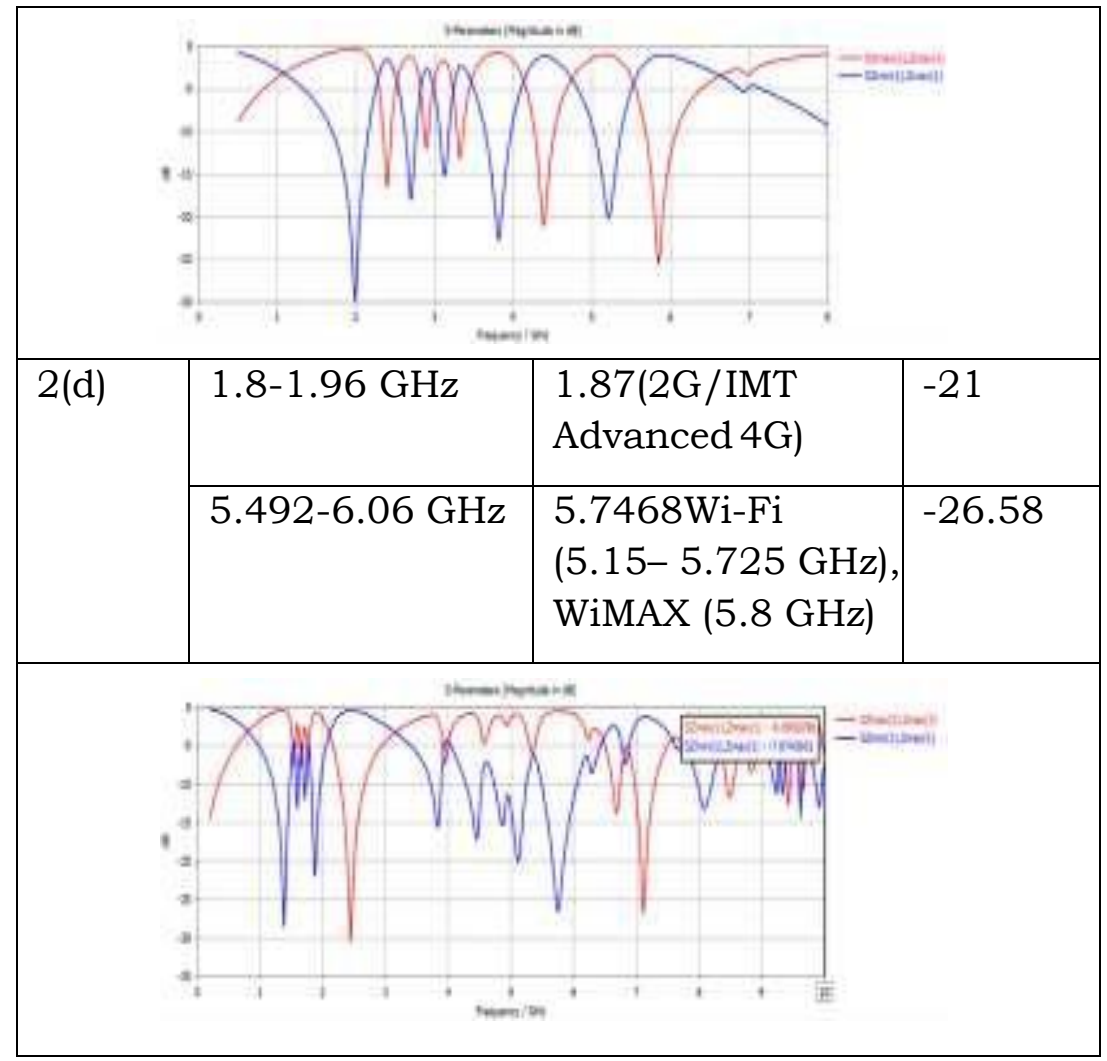

C. Results of Designs 3(a) to (c)

Table 5 shows the range of frequencies stopped, and value of scattering parametersin $\mathrm{dB}$, for the simulated designs $(\mathrm{m})$ to $(\mathrm{o})$.

Table 5. Details obtained from Scattering Parameter Graph and Graphical representation of parameters obtained

\begin{tabular}{|l|l|l|l|}
\hline Design Name & $\begin{array}{c}\text { Range of Frequencies } \\
\mathbf{( G H z )}\end{array}$ & Mid Frequency (GHz) & \multicolumn{1}{|c|}{ S11 (dB) } \\
\hline \multirow{3}{*}{$3(\mathrm{a})$} & $1.22-1.47$ & $1.389(\mathrm{GPS})$ & -25 \\
\cline { 2 - 4 } & $4.28-5.32$ & $5.17(\mathrm{Wi}-\mathrm{Fi})$ & -17 \\
\cline { 2 - 4 } & $7.11-8.24$ & $7.91(\mathrm{X}-\mathrm{Band})$ & -28.10 \\
\cline { 2 - 4 } & $5.32-6.52$ & $6.20(\mathrm{WiMAX})$ & -31.06 \\
\hline
\end{tabular}




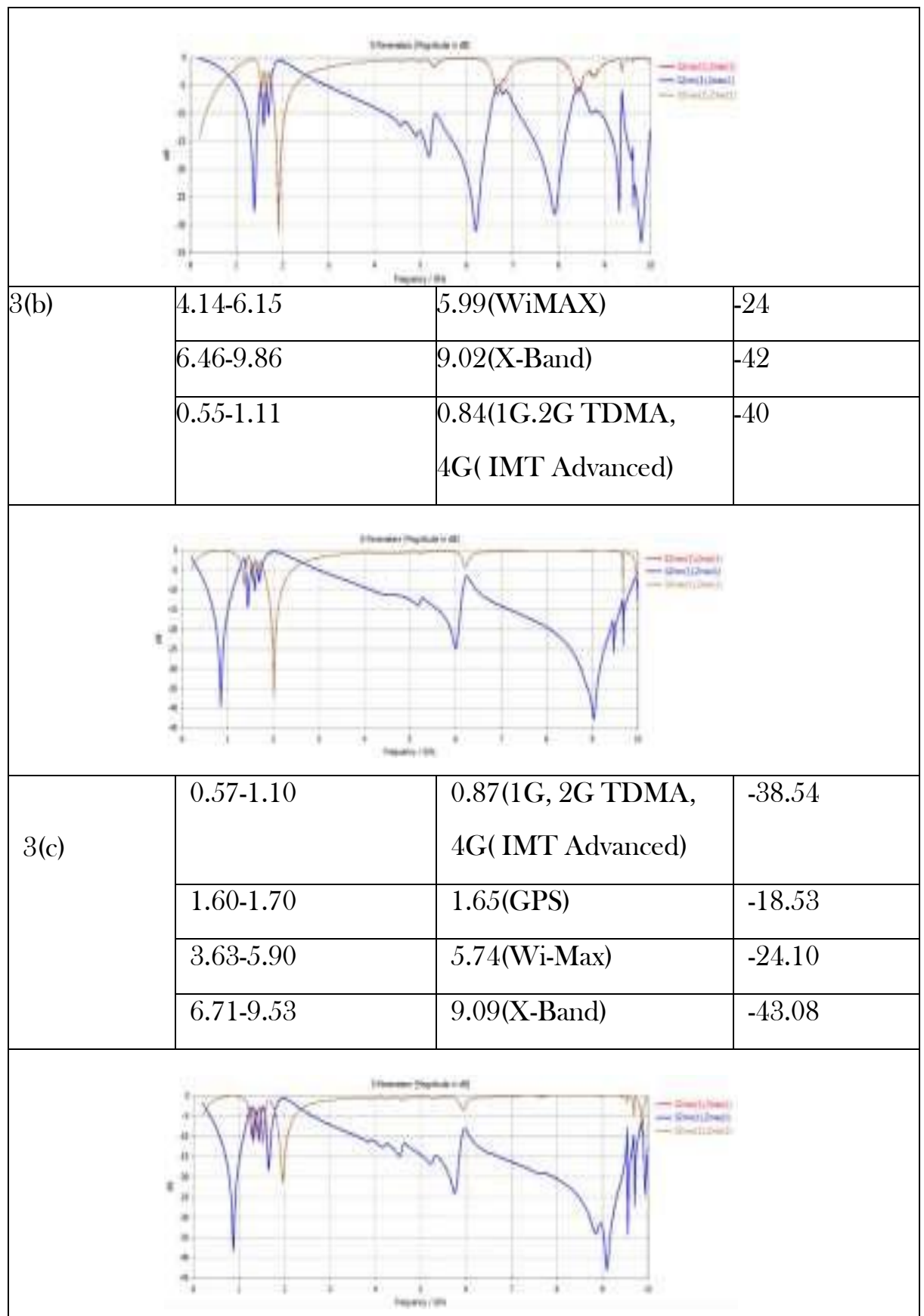

The design 3(a) is stopping the following frequencies $2.38,5.17,7.91,6.20$ with good stability at TE and TM mode as shown in the graph similarly design 3(b) is stopping the following frequencies 5.99, 9.02, 0.84, with good stability at TE and TM mode as shown in the graph and design 3(c) is stopping the following frequencies $0.87,1.65,5.74,9.09$ with good stability at TE 
and TM mode as shown in the graph. This confirms that carefully designed single frequency loops when combined in two can give better frequency response on stop multiple frequencies. On the other back hand designs i.e., designs on the both side of substrates. Can provide better shielding to wide bands of frequencies. And can be a viable option for future wide band application designs. The key to process success is carefully choose the design for single frequency, match the design for multiple frequencies, superimpose and then optimize the back design for the remaining frequencies. Closer the Omega $r$ (resonance frequency) to previously superimposed design, better is the value of S11 parameters for band stop FSS.

\section{Conclusion and Future Work}

The various designs using copper (annealed) with resistivity, $\rho=8930 \mathrm{~kg} / \mathrm{m}^{3}$, as a conducting line and FR4 (lossy) with relative dielectric constant, $\varepsilon_{\mathrm{r}}=4.3$, as a dielectric substrate are simulated.

Using different approach, it was observed that as the conductive lines in the patch increases the continuity in S11 parameter decreases, however in spite of that the transmission parameter remain almost near $0 \mathrm{~dB}$, when the conductive lines were added on the back side of dielectric.

This indicates that a better band stop FSS can be obtained by individually finding out center frequency for single loops and then merging them together to form a dual side FSS structure.

\section{References}

[1] Arshad, Q. K. U. D., Kashif, A. U., \& Quershi, I. M. (2019). A review on the evolution of cellular technologies. In 2019 16th International Bhurban Conference on Applied Sciences and Technology (IBCAST), IEEE. 989-993. https://doi.org/10.1109/IBCAST.2019.8667173

[2] Gawas, A. U. (2015). An overview on evolution of mobile wireless communication networks: 1G- 6G. International Journal on Recent and Innovation Trends in Computing and Communication, 3(5), 3130-3133.

[3] Li, X., Gani, A., Salleh, R., \& Zakaria, O. (2009). The future of mobile wireless communication networks. In 2009 International Conference on Communication Software and Networks, IEEE. 554-557. https://doi.org/10.1109/ICCSN.2009.105

[4] Juneja, S., Pratap, R., \& Sharma, R. (2020). Semiconductor technologies for 5G implementation at millimeter wave frequencies-Design challenges and current state of work. Engineering Science and Technology, an International Journal, https:/www.Xmol.com/paperRedirect/1286788124931440640 
[5] Kumar, V. C. P., Kumar, B. S., Reddy, V. M., \& Prasad, G. G. (2021). Reconfigurable tri-band monopole antenna for LTE and WiMAX applications using FR4 material. Materials Today: $\quad$ Proceedings, $\quad 39, \quad 513-519$. https://doi.org/10.1016/j.matpr.2020.08.247

[6] Biswas, A., \& Gupta, V. R. (2019). Multiband antenna design for Smartphone covering 2G, 3G, 4G and 5G NR frequencies. In 2019 3rd International Conference on Trends in Electronics and Informatics (ICOEI), IEEE. 84-87. http://dx.doi.org/10.1109/ICOEI.2019.8862713

[7] Balta, Ş., \& Kartal, M. (2019). A Novel Multilayer Multiband Frequency Selective Surface for IMT Advanced 4G Mobile Phone Service and Airborne Radar Systems. In 2019 9th International Conference on Recent Advances in Space Technologies (RAST), IEEE, 527-531. https://doi.org/10.1109/RAST.2019.8767860

[8] Nandhini, E., Sreeja, B. S., Jose, M. C., \& Radha, S. (2019). Implementation of Aperture coupled Stacked layer Microstrip Patch Antennas for 5G Wireless Communication Systems. In 2019 International Conference on Vision Towards Emerging Trends in Communication and Networking (ViTECoN), IEEE. 1-5. https://doi.org/10.1109/ViTECoN.2019.8899358

[9] Alibakhshikenari, M., Limiti, E., Naser-Moghadasi, M., Virdee, B. S., \& Sadeghzadeh, R. A. (2017). A new wideband planar antenna with band- notch functionality at GPS, Bluetooth and WiFi bands for integration in portable wireless systems, $A E U$ International Journal of Electronics and Communications, 72, 79-85. http://dx.doi.org/10.1016/j.aeue.2016.11.023

[10] Asnani, V., \& Baudha, S. (2019). Triple Band Microstrip Patch Antenna Useful for Wi$\mathrm{Fi}$ and WiMAX. IETE Journal of Research, 1-8. https://doi.org/10.1080/03772063.2019.1582365

[11] Farooq, U., Iftikhar, A., Shafique, M. F., \& Mughal, M. J. (2019). A miniaturized and polarization insensitive FSS and CFSS for dual band WLAN applications. AEUInternational Journal of Electronics and Communications, 105, 124-134. https://www.Xmol.com/paperRedirect/1308189487397048320

[12] Kanchana, D., Radha, S., Sreeja, B. S., \& Manikandan, E. (2019). Convoluted FSS Structure for Shielding Application In X-Band Frequency Response. IETE Journal of Research, 1-7. https://doi.org/10.1080/03772063.2019.1691062

[13] Singh, R., Bahel, S., Narang, S.B. (2019). Dielectric and microwave reflection properties of M-phase LNT (Li- Nb-Ti-O) solid solutions in X-band frequency range. Journal of Alloys and Compounds, 784, 668-675. https://doi.org/10.1016/j.jallcom.2019.01.020 
[14] Aggarwal, N., \& Narang, S. B. (2020). Magnetic characterization of Nickel-Zinc spinel ferrites along with their microwave characterization in Ku band. Journal of Magnetism and Magnetic Materials, 513, 167052. https://doi.org/10.1016/j.jmmm.2020.167052

[15] Almeida Filho, V. A., \& Campos, A. L. P. (2014). Performance optimization of microstrip antenna array using frequency selective surfaces. Journal of Microwaves, Optoelectronics and Electromagnetic Applications, 13 (1) 31-46.

[16] Deng, R., Xu, S., Yang, F., \& Li, M. (2018). An FSS- backed Ku/Ka quad-band reflectarray antenna for satellite communications. IEEE Transactions on Antennas and Propagation, 66(8) 4353-4358. https://doi.org/10.1109/TAP.2018.2835725

[17] E. H. Miller, A note on reflector arrays, IEEE Trans. Antennas Propagat, inpress.

[18] Singh, C., Jha, K. R., Sharma, S. K., Jibran, Z. A. P., \& Singh, G. (2020). Design of a wideband square slot bandpass frequency-selective surface using phase range analysis. Engineering Reports, 2(1), e12085. https://doi.org/10.1002/eng2.12085

[19] Munk, Ben A. (2005). Frequency selective surfaces: Theory and Design. John Wiley \& Sons, New York. https://doi.org/10.1002/0471723770

[20] Tajuddin, S. R., Azemi, S. N., Soh, P. J., Rashidi, C. B. M., \& Al-Hadi, A. A. (2019). Analysis and design of directive antenna using frequency selective surface superstrate. Indonesian Journal of Electrical Engineering and Computer Science, 14(2), 529-536. http://doi.org/10.11591/ijeecs.v14.i2.pp529-536

\section{Acknowledgements}

The authors declare that they have no conflict of interest.

\section{Conflict of interest}

The authors declare that they have no conflict of interest.

\section{About The License}

(C) 2021 The Authors. This work is licensed under a Creative Commons Attribution 4.0 International License which permits unrestricted use, provided the original author and source are credited. 